\title{
Further Discoveries of the Neolithic and Bronze Ages at Peterborough
}

\author{
By.E. T. LeEds, M.A., F.S.A.
}

[Read 12th January 1922]

IN I $910 \mathrm{Mr}$. G. Wyman Abbott read to this Society a paper in which he gave some account of his discoveries of early British remains at Fengate, Peterborough (see Archaeologia, lxii, $35^{2}$ ff.). Since that date he has been assiduous in collecting from the same locality such further material as has been brought to light in the process of gravel-digging. This new material already serves to indicate that the site was occupied continuously from Late Neolithic down to Late Celtic times, and, if only for that reason, is of the highest importance, since it is but seldom that a site with signs of habitation covering so long a period comes to light in this country.

The collections formed by Mr. Abbott are too extensive to admit of their being treated within the limits of a single paper, and it is proposed to defer consideration of the finds belonging to the latter part of the Bronze Age and the Early Iron Age to a future time. The present account will be restricted to such new discoveries as link on to those already published in I $\mathrm{g} \mathrm{IO}$, particularly as they serve to throw fresh light on that as yet very imperfectly known subject, the pottery in use in Britain before the coming of the beaker-people.

Mr. Abbott has honoured me by inviting me to undertake the pleasant task of describing his finds, and this task has been made comparatively simple, inasmuch as he has placed all his notes and sketches at my disposal, and has given me the benefit of the views formed by himself from long acquaintance with, and acute observation of, the material and the circumstances of its discovery.

The site, as seen when set out on a rough plan, is so confused that it is impossible to say that any special portion of it was occupied exclusively at one period. The recorded finds of the Neolithic and Bronze Ages, with the exception of one particular section of the Neolithic material, seem to be distributed indiscriminately over the whole area without rhyme or reason. 
Up to the present time the Iron Age finds are more restricted in their distribution-that is to say, they are not found in all parts of the site, but there is nothing to indicate a shifting of the ground occupied, since these later finds are interspersed with others of early date in close proximity to one another. In fact it is almost a miracle that the relics of the earlier ages have survived at all. Worked flints are found scattered over the whole area and are of common occurrence in the pot-holes. It is impossible to assign any particular date to the flints, scattered as they are, since the areas of occupation are so intermixed that any given flint might have been used in any period.

The flints found include:

(a) Three arrow-heads, two of them barbed and tanged, and one tanged only. Several crude leaf-shaped arrow-heads.

(b) Scores of scrapers of all types and shapes.

(c) Knives of a primitive type.

(d) Saws. A large number of these came from one particular area along with two pieces of flint celts.

All the flints are unpatinated and usually lustreless and dull. Quantities of burnt stones are found in the pits or hut-circles interspersed in the dark soil, in which also frequently lumps of clay appear. These may be material used for pottery-making or daub from the walls and roofs of huts.

Neolithic. The discoveries were made for the most part in pits, of varying diameter and depth, of the usual hut-dwelling type. As examples have already been described in Archaeologia, lxii, 333, it is unnecessary to dilate on their form here.

Mr. Abbott has observed that the Neolithic remains, chiefly pottery, come from an old land-surface or from small pot-holes (the lower portions of cooking-holes) which are the remnants of excavations dug in Neolithic times and which had been cut down and levelled by later inhabitants of the site.

The pottery is always fragmentary, only scattered pieces being found as a rule and at a depth not exceeding two feet from the surface of the soil. In no instance has Neolithic pottery been found with a burial.

The special class of pottery described below in $\oint$ vi, on the other hand, has been found solely in one particular area and in excavations filled with black soil.

It is more particularly with the pottery that the present paper is intended to deal, since both the quantity that has been brought to light and the wide variation of the decoration seem to contain within itself the whole history of the final stages of the pottery of the Late Neolithic Period and also afford a remarkable insight 
into the elements of Neolithic ceramic which survived in that of the Bronze Age. Mr. Reginald Smith has already described a part of these survivals in his study of the evolution of the foodvessel from the Neolithic round-bottomed bowl (Archaeologia, lxii). The new material not only allows us to establish other survivals, but also, as it were, to construct a genealogical tree of the Neolithic pottery itself.

I. The earliest pottery from Peterborough consists of several fragments found together in one pit, with flakes of light brown flint and small black flint scrapers. The pottery itself is of badly

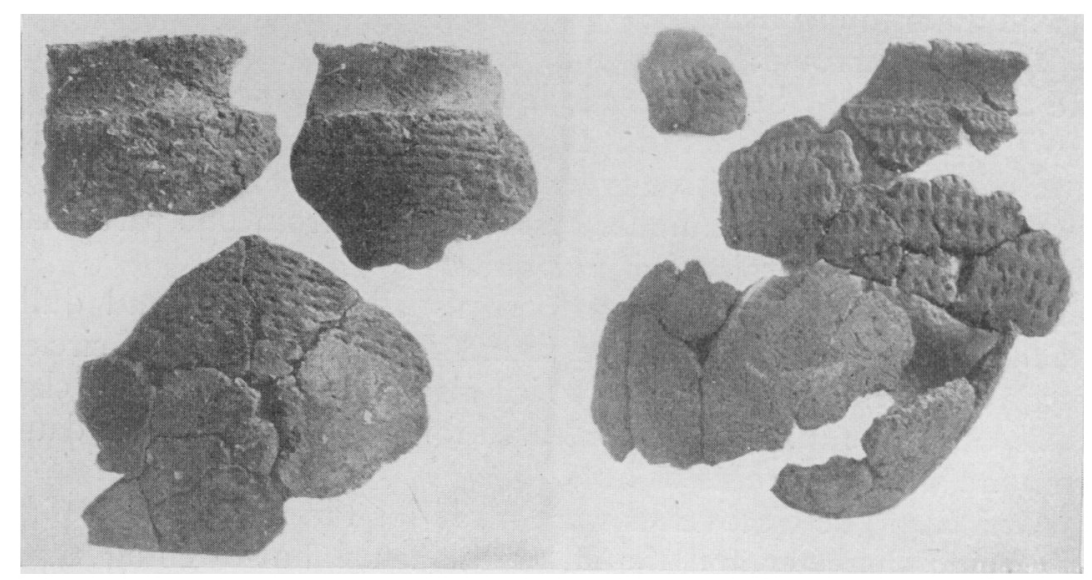

FIG. I.

FIG. 2.

compounded soft black paste containing large pieces of quartz, and belongs exclusively to round-bottomed bowls (fig. I). ${ }^{\mathrm{I}}$

(a) Exterior surface, brown; interior, black; decorated below the neck with nine rows of horizontal lines impressed by means of a cord.

(b) Exterior, chestnut-brown; interior, black ; some twelve rows of horizontal cord-impressions about $\frac{1}{4} \mathrm{in}$. long. This curious type of decoration also occurs on the lower part of a small Bronze Age vase (for type see Abercromby, i, plate XXIX, fig. I), found at Whittlesea, Cambridgeshire, and now in the Peterborough Museum.

(c) Exterior, grey, abraded ; interior, brown ; decorated with rows of horizontal cord-impressed lines.

x Reference should be made throughout to fig. I 2 , in which sections of the pottery described are given. The Roman numerals refer to the sections in the text, the letters to sub-sections; the figures in brackets to the other illustrations. 
Besides the common features of horizontal decoration and imperfect firing, all three sherds show a deeply constricted neck with a very pronounced carination at the shoulder, and all are characterized by the complete absence of any ornamentation above the shoulder, on the lower half of the body, or on the interior of the rim.

II. This class is represented by finds at two points of the site, the first close to that which yielded the fragments placed in Class $I$, and the second from the bottom of the pit from which came the fine fragments of beakers described in Archaeologia, lxii.

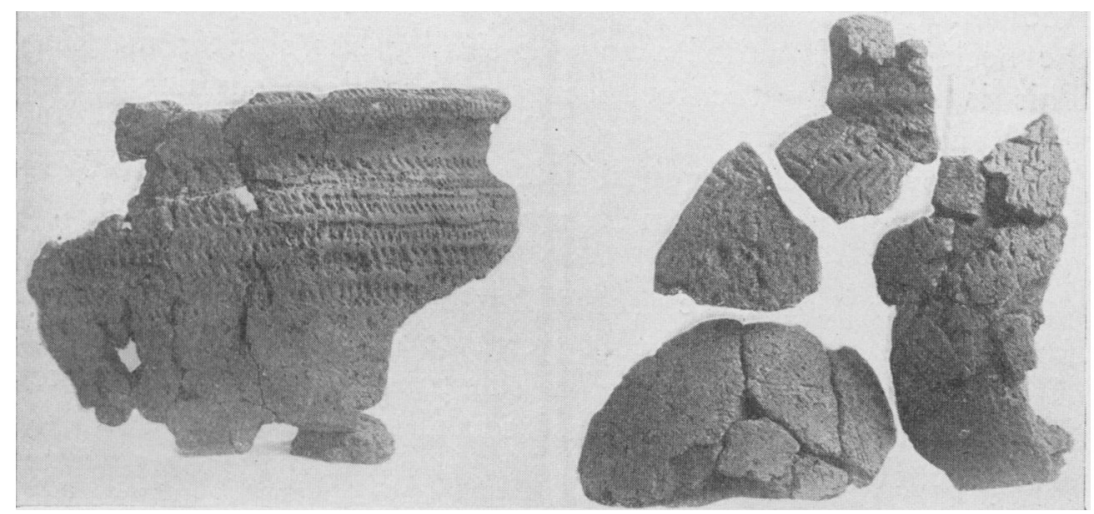

FIG. 3.

FIG. 4.

They comprise portions of Neolithic bowls, exhibiting the same imperfect firing as Class I, but made of a paste free from gritty lumps and showing an advance in form and decoration. The base may be round, but in some cases flat.' The ornamentation consists of horizontal rows of herring-bone or of almost vertical dashes (fig. 2) in cord technique, with one row of diagonal strokes impressed on the lower part of the curve of the neck just above the shoulder. The curve of the neck is less pronounced; the rim is thick, rounded, and undecorated. The fragment of a bowl (restored in Archaeologia, lxii, p. 336, fig. 3) belongs to this class, and in Mr. Abbott's opinion should have been shown without decoration on the rim.

A variant of this class appears in pieces of bowls from a pit, $5 \mathrm{ft}$. deep and $\mathrm{I} \circ \mathrm{ft}$. in diameter, situated close to the sites of the discovery of Class I and most of Class II. They only differ in

I This applies to the largest size of bowls and may be due to the weight of the pot before firing. 
the addition of ornamentation on the interior face of the rim in the form of herring-bone or diagonal strokes.

III. Part of a large bowl (fig. 3), almost I ft. in diameter, found in 1920 at a depth of about I ft. 9 in. below the surface of the gravel at another part of the site, seems to mark a distinct advance, since the exterior surface is red in colour, evidencing better firing of the vase. The interior varies from black to grey. The decoration is still restricted to the upper part of the body and consists of two rows of herring-bone in cord technique deeply impressed. The impressions are thickly set, but seem to go in pairs, the members of which are so close as almost to interlock. Above a line of diagonal strokes on the lower part of the curve of the neck there is added a row of similar but shorter markings. This is evidently the forerunner of the deep circular pittings which appear commonly on Neolithic bowls of a late class (cf. the bowl from Mongewell in Archaeologia, lxii, plate XXXVIII, fig. 3 , and fragments from Peterborough in ibid., p. 345, figs. I 2 and 13 ).

The upper part of the neck still remains undecorated; the rim, however, has now a bevelled outer face and a flattened top, both of which are ornamented with chevrons or diagonal strokes; internally a line of chevrons has been placed below the rim.

A recent discovery (see fig. I I), since this paper was written, exhibits a hark-back from the point of view of the undecorated neck, but the section of the vase, as also the incised design, puts it at once among the later examples of this pottery. The disorderly tangle of lines is in reality a representation of the herringbone motive, such as is often found on late Neolithic vases. On the inside of, the rim the herring-bone motive remains true to type.

IV. The foregoing material, while presenting some new aspects of Neolithic pottery, belongs mainly to known forms from which the descent of the British food-vessel can be traced. A recent find at Peterborough, however, brings us face to face with a striking development within the Neolithic Period, which throws entirely fresh light upon vases discovered by Mortimer in the course of his excavations on the wolds of the East Riding.

It is no less than a portion of a large vase, probably with flat base, estimated to have been, when perfect, over $\mathrm{I} f \mathrm{ft}$. in height and some $7 \frac{1}{2}$ in. in diameter (fig. 4). It has a deep, rounded rim connected with the body by a shallow constriction, a relic of the deep neck of the earlier bowls. The upper part of the vase is ornamented as far as a point just below the shoulder with four rows of herring-bone pattern, no portion of the constriction being left unornamented. 


\section{FURTHER DISCOVERIES AT PETERBOROUGH 225}

The body was cylindrical or barrel-shaped, and, in addition to the single row of herring-bone pattern below the shoulder, was decorated for some $5 \frac{1}{2}$ in. with irregular rows of vertical finger-nail

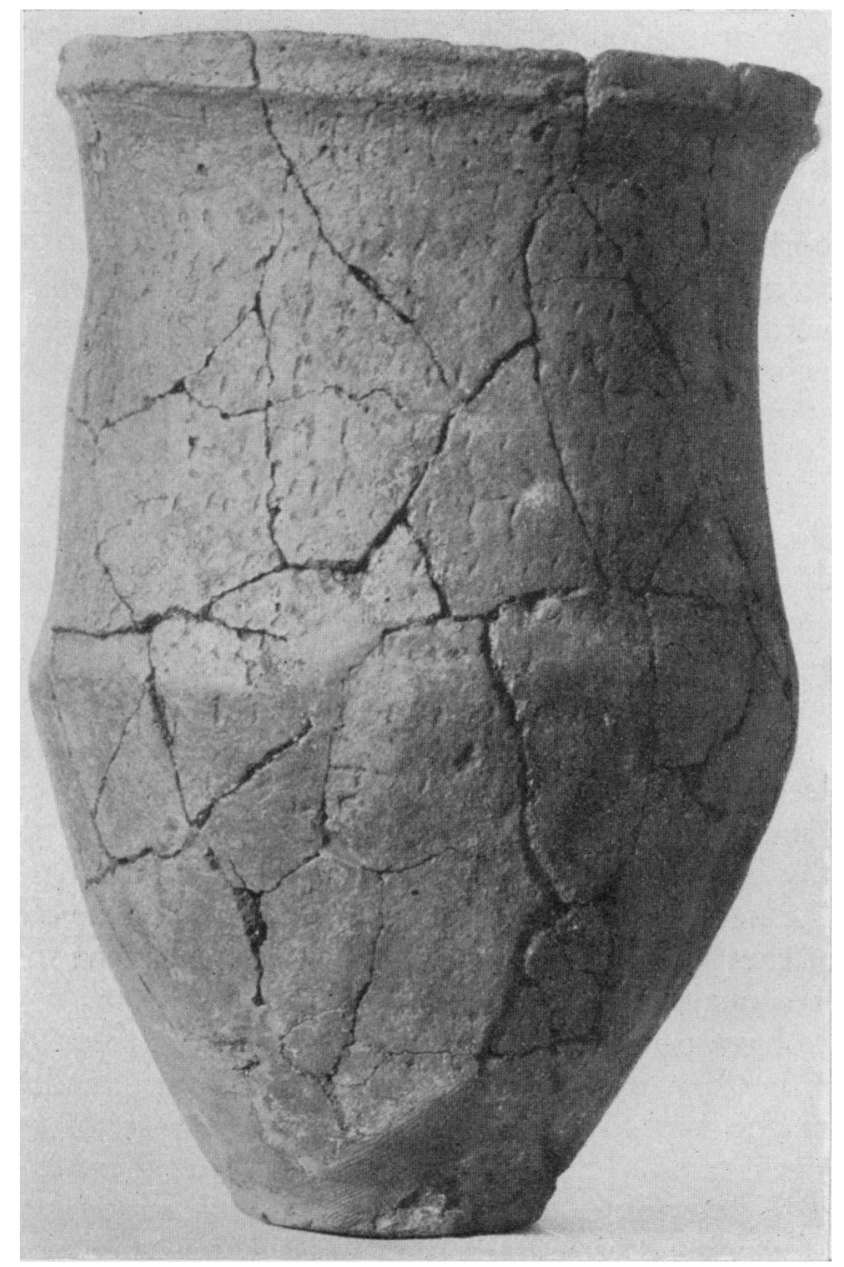

FIG. 5. Beaker from Peterborough (abou: $\frac{1}{3}$ ).

incisions, but still the decoration does not extend to the lower part of the vase.

In this remarkable vase we have an exact counterpart to that discovered by Mortimer a few inches above one of the primary interments in Barrow no. 98 on Painsthorpe Wold (Forty Years, fig. 335), except that the Yorkshire vase, which measures 8 in. in vOL. II 
height, is decorated only with herring-bone, in itself a survival, and has the constriction left plain. It may be that the burials in this barrow are thus of the very earliest Bronze Age with Neolithic survivals, or even that food-vessels of the type (op. cit., fig. 336) found in grave $\mathrm{B}$, immediately below the large vase, belong in reality to the transition period. The decoration of the inside of the rim of the Yorkshire vase with a lozenge pattern executed in two parallel lines in cord technique is to be noted, as similar decoration occurs on pottery from Peterborough to be described immediately. The lower part of the Yorkshire vase, like that of the Peterborough example, is left plain.

V. That at this stage in the development of Neolithic pottery the continental influences brought by the beaker-people assert themselves is indicated by what is perhaps the most remarkable vase as yet recovered by $\mathrm{Mr}$. Abbott from the Peterborough site (fig. 5).

It was found in 1916 in an upright position in a bowlshaped hole, about $4 \mathrm{ft}$. deep and $5 \mathrm{ft}$. wide, filled with the usual dark soil. The vase is nothing less than a huge beaker, 15 in. high and $\mathrm{ro}$ in. across at the greatest diameter of the belly and at the mouth. It is of fairly good paste, but not with the fine gritty texture of the highly ornamented beaker-fragments described in Archaeologia, lxii ; it is fired red both inside and out, and is decorated with nine irregular rows of short vertical incisions, the ornamentation reaching to the swell of the belly. Noteworthy is the grooved collar at the rim. In short, this vase, while of the newly-introduced shape, in all else retains clearly the features of the Neolithic ceramic, though in a decadent form, such as might reasonably be expected.

VI. We have now to retrace our steps in order to examine two groups of pottery which, while undoubtedly of Neolithic date, differ from the types which head the preceding series in several important respects. Their exact relation to the other series is not quite easy to determine, but certain indications suggest that they come in at a point a little later than Class III, and in some cases almost certainly earlier.

(a) The finest of these groups comprises sherds of black, medium hard paste of uniform texture with no lumps of grit; some fragments are burnt to a pale red on the outside. They belong to two or three pots, and such rims as have been preserved are thin and of almost uniform thickness, tapering but slightly to the upper edge. These rims are portions of deepcollared vessels like many Bronze Age cinerary urns. The decoration is in every case incised. In one example we have 
a collar with seven horizontal lines and, on the body below, herring-bone pattern (fig. $6 a$ ); another, also part of a rim, shows a succession of six wide-angled, inverted chevrons set one within another, with horizontal strokes between the uppermost chevron and the edge of the rim (fig. $6 b$ ); while rows of short, vertical, jabbed incisions decorate a third (fig. $6 c$ ). Two fragments indicate flat bases; one with vertical walls and a groove at the junction of the walls and the base is figured (fig. $6 d$ ).

(b) More important is the second group, which came from two pits measuring $4 \frac{1}{2} \mathrm{ft}$. in depth and some ro ft. in diameter, and situated $2 \mathrm{ft}$. apart from one another. In one of them, in an oval grave at the bottom of the pit, was found a skeleton lying in

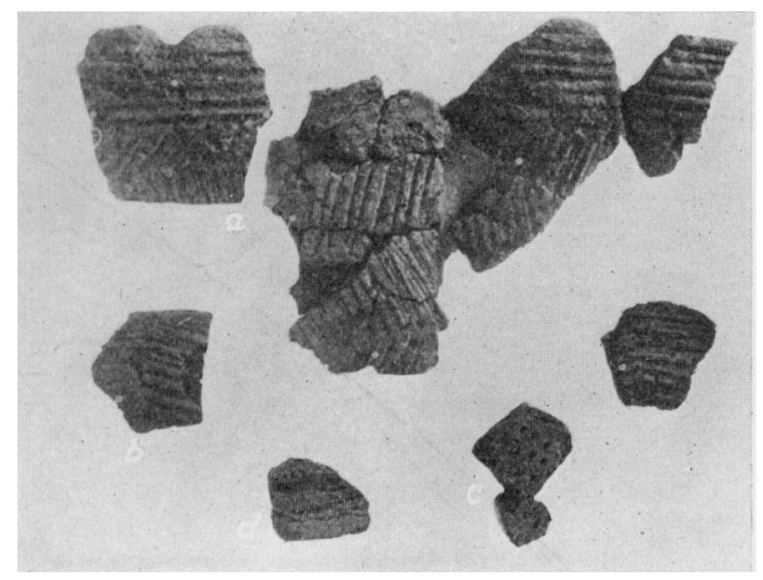

Fig. 6.

a contracted position on its right side with the head to the east. Another pit close by contained the burial of a young person.

The filling of the pits yielded numerous fragments of pottery; in no case could a complete pot be reconstructed, the inference being that they were parts of broken domestic pottery. The ware is for the most part of a badly baked, thick variety, with plain body and highly ornamented rim, though a few pieces point to decoration of the body of the vase as well. The paste is always coarse black, sometimes hard baked with lumps of quartz mixed in the clay, sometimes almost pure and very soft. The colour after firing varies from brown to light brown and to dark red.

The sherds appear to belong to vessels of three main types:

(1) Bowls of the well-known Neolithic type with constricted neck and with round (or flat) bottom. They vary, however, in one 
important respect. The rim, instead of being round or polygonal in section, is bevelled upwards to the edge of the interior wall, which falls in a vertical line downwards. The bevelled face is decorated with herring-bone pattern, as is also the neck and upper part of the body; below that point the lines of the pattern intersect one another (fig. $7 a-b$ ). The whole of this decoration is carried out in incised lines; only on the interior of the rim are some very imperfectly executed cord-markings to be found. This appearance of linear incision marks an important stage in what may be termed the decadence of the Neolithic bowl. Similarly, the careless execution of the pattern, as also the form of the rim, seem to characterize a late form of these bowls, as exemplified by

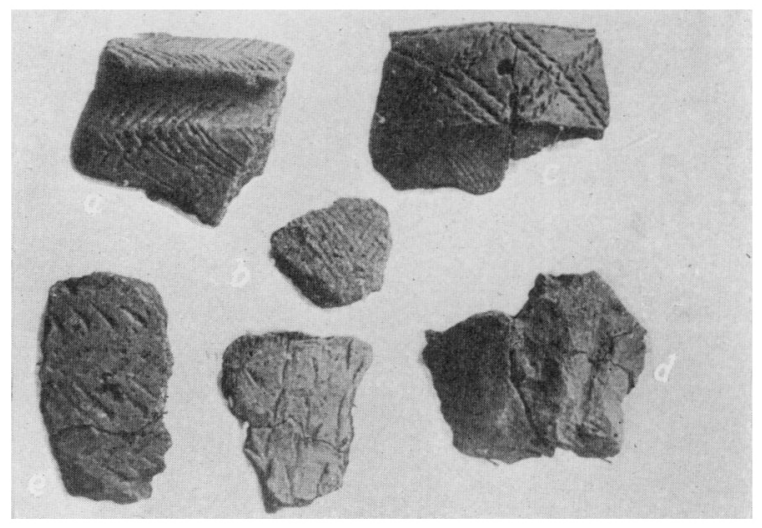

FIG. 7.

the bowl from Upper Swell, Gloucestershire, in the British Museum, and together with the linear incised ornament furnish an initial clue to the date of other pottery from the same group of pits.

(2) Bowls with curved sides and no constriction below the rim; inturned rims bevelled on the inner face. This bevelled edge is decorated with herring-bone or 'wheatear' motives, made with the finger-nail or finger-tip and so deeply impressed as to give the outer edge of the rim an indented appearance. The exterior ornamentation is limited to some two inches in depth at the top of the vase. The designs, which are incised, partake of the nature of hatched triangles, but a noticeable trait is the tendency to curvilinear execution (fig. $8 a$ ).

(3) Vessels like the earliest cinerary urns of the Bronze Age, with deep collar and with a slight constriction immediately below and 
usually plain body. The rim may be slightly curved in section, with a gently bevelled edge as in the bowls of type (2), or with a steeply bevelled edge, in both cases commonly decorated with herring-bone design; or the rim is almost vertical, slanting but a little inwards towards the top, which has a curved edge, too narrow for decoration.

It is in this class that the curvilinear ornament is most conspicuous. One example shows hatched triangles with an intervening design of concentric curves (fig. $8 \mathrm{~b}$ ); another groups of concentric elliptical curves, the intervals filled up with herringbone motive (fig. 9). Less ambitious are two vases, one of which, of soft black paste, burnt to a reddish black, has the rim covered

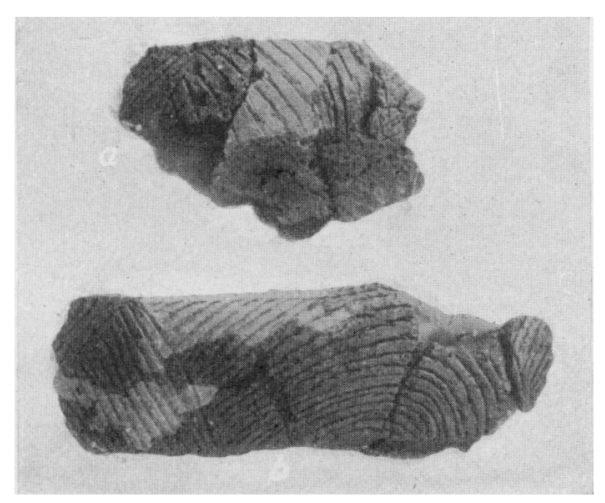

FIG. 8 .

with finger-tip impressions, while on the other, of hard black paste, the finger-nail has been used. In all these the finger or nail has been the sole implement employed; even the curved and straight lines have been painstakingly executed by this means, and the herring-bone pattern for which elsewhere the cord is almost invariably used is made in the same way.

Cord decoration is, however, not unknown. It appears on one vase in striking form, in a lozenge pattern with a central dot. In the lower angle made by the junction of each pair of lozenges is inserted an additional inverted chevron. The body of the vase is, unlike the majority of the type, decorated; from such fragments as have been preserved, the design seems to have a tall zigzag pattern, lightly incised with a six-toothed comb (fig. $7 c-d$ ). On other sherds the same technique is apparent in diagonal bands 
(e. g. fig. $7 e$ ). Cord-impressed decoration was also employed for parallel diagonal lines on the collar of another vase.

A restored vase of this class (fig. IO) and part of another have their rims decorated with vertical incisions or finger-markings.

Apart from the deductions which can be drawn from the material already described, further important clues to the date of this group of pottery are available.

The first of these is furnished by a fragment of the base of a well-fired, dark red vase, on which is a horizontal line of decoration impressed with a square-toothed implement, probably of semicircular form. ${ }^{\mathrm{T}}$ Decoration in this technique is so essentially characteristic of the Bronze Age pottery and is so entirely foreign

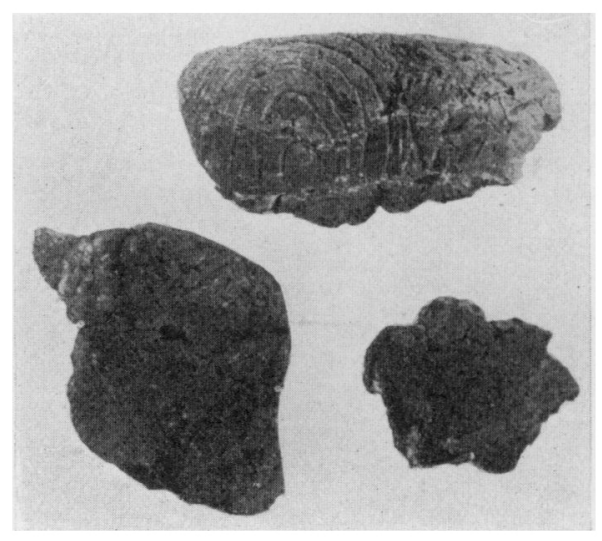

FIG. 9.

to Neolithic ceramic, that we are forced to the conclusion that we are here at the parting of the ways, but it must always be borne in mind that the introduction of the beakers and of bronze are not necessarily synchronous. Further, two fragments of polished celts were associated with this pottery; one, of grey flint, is the butt-end of the common thin-butted type (Evans, Ancient Stone Implements, fig. 45); the other, part of the shaft of a narrow celt, or possibly chisel, of white cherty flint, is roughly quadrangular in section, with two wide slightly convex faces, and two narrower edges approximately flat, one of them chipped only. A large, somewhat flat, fint scraper, varying in colour from black to grey, and of pentagonoid outline, $2 \frac{1}{2} \mathrm{in}$. in width and $\frac{1}{2} \mathrm{in}$. thick, as well as numerous serrated flakes, constitute part of the same find.

I The line is less deeply impressed at the ends than at the middle. 
While the scheme put forward above for the differentiation of Neolithic pottery is, in view of our, as yet, imperfect knowledge of the subject, admittedly tentative, the Peterborough pottery seems to bear all the signs of its makers advancing in ceramic skill by gradual stages, at each of which some fresh contribution was added, whether in improved methods of firing or in decorative ideas. In the latter stages the progress becomes more marked and is clearly the result of the incoming continental influences.

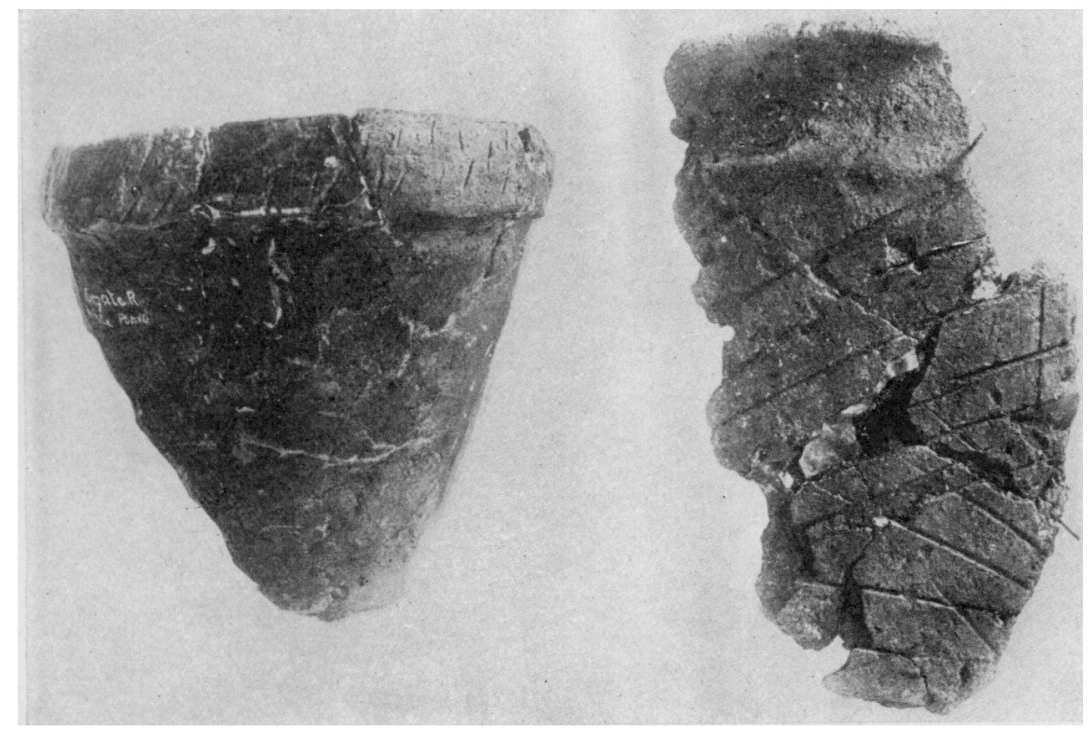

Fí. 10.

FIG. II.

It is interesting to note further evidence of connexions with Yorkshire, already suggested by the food-vessel from a barrow at Eyebury (Proc. Soc. Ant., xxvii, p. I I 9, fig. 3). Mr. Abbott has drawn my attention to yet another parallel furnished by sherds, such as that figured in Archaeologia, lxii, p. 345, fig. 9, of vases with vertical walls and a sharply inturned lip. They are identical with sherds found by Mortimer in barrow no. 30 in the Aldro group (Forty Years, fig. I 42), and barrow no. 2 I I on Acklam Wold (ibid., fig. 2 I 9). In both cases these were found in holes, not used for interments, under the floor of the barrow, and thus presumably are earlier than the barrow itself. Further, it is to be noted that the fragment from Acklam Wold shows the unusual curvilinear pattern and that from Aldro incised chevron decoration on 
the interior of the vase, both of which features are unknown to Bronze Age pottery.

The significance of the curvilinear phase in the decoration of British Neolithic pottery is not easy to explain. Something similar occurs on vases from Neolithic cists in Arran (P.S. A. Scot.,

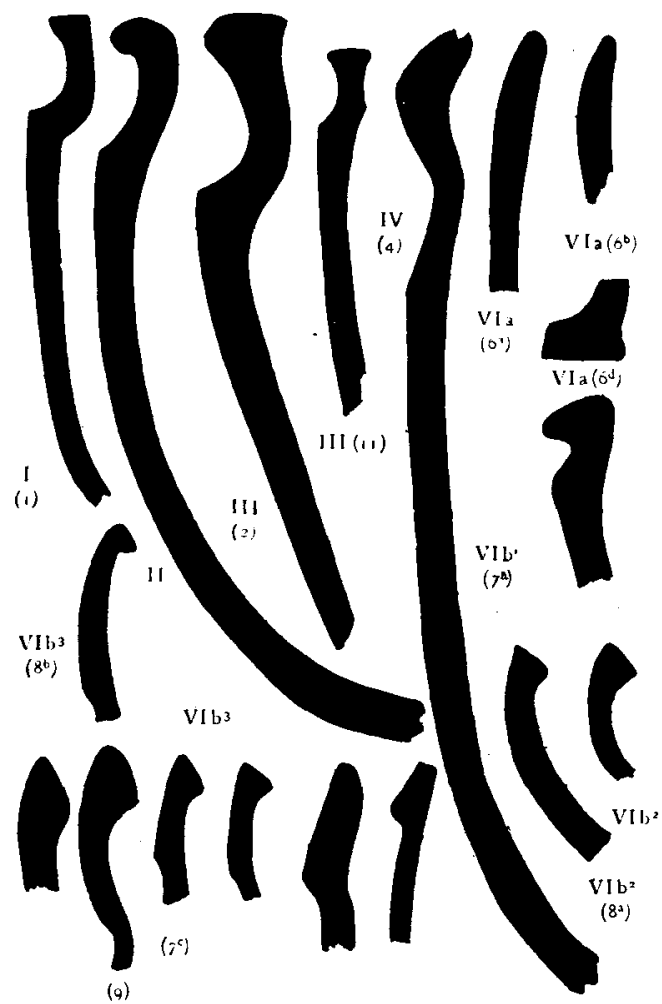

FIG 12. Sections of Neolithic Pottery from Peterborough $\left(\frac{1}{3}\right)$.

[Rom.n numerals refer to the main sections; letters, \&c., as $b^{3}$, to subsections; numerals in brackets to the other illustrations]

I 902, p. I05, fig. 3I, and p. I09, fig. 37), but as yet it is only of rare occurrence in these islands. When we seek for parallels on the Continent, the nearest approach is the decoration on a vase from the dolmen du Conguel, Morbihan (P. Chatellier, La Poterie aux époques préhistoriques et gauloises en Armorique, plate VII, fig. I3), but it is almost too far a cry from north-west France to Arran to see a connexion in the occurrence of this type of decoration at these two points, even on the bașis of megalithic diffusion, without 
some intervening examples. In any case it will hardly serve to explain its presence at Peterborough, which lies entirely outside the area of the megalithic monuments in the British Isles. Further material is yet needed before a solution of this interesting variety of ceramic can be reached.

Bronze Age. In addition to the richly ornamented fragments of beakers published in the previous account of Mr. Abbott's discoveries further sherds of the same nature were recovered from a pit situated at no great distance from that in which the earlier finds were made. They are decorated with incised cross-hatched

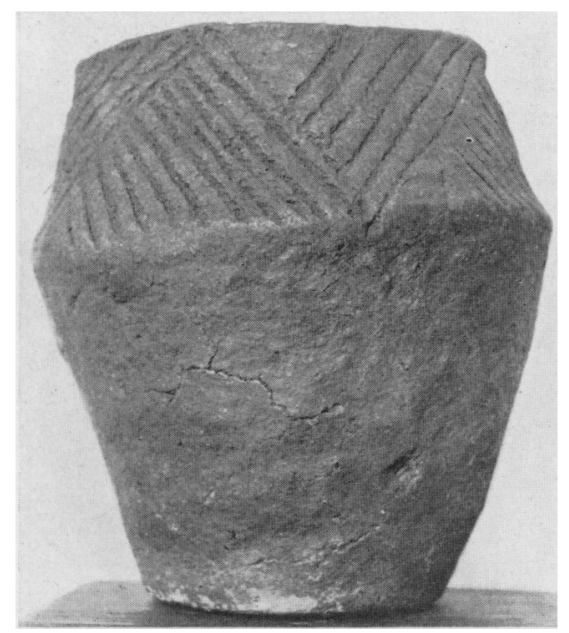

F1G. 13. Urn from Peterborough.

patterns and others executed with a toothed implement. Some ten yards away in a small hole about $3 \mathrm{ft}$. deep, filled with black soil, a small vase was found resting on the top of the gravel. This pot is of biconoid form, and is made of a gritty paste baked to a yellowish red with black patches. It measures 6 in. in height; the diameter varies from 4 in. across the mouth to 5 in. at its greatest width at the carination of the vase, whence it tapers off to $3 \frac{1}{4}$ in. across the base. The decoration, executed in cord technique, is confined to the upper part of the vase and consists of triangles alternating up and down and hatched in opposite directions (fig. I 3 ).

Several burials are recorded, but unfortunately only in a few instances has Mr. Abbott been able to be present when the skeleton was unearthed, although he succeeded in obtaining 
sufficient information from the gravel-diggers to reconstruct some of the others. Thus in one case the body lay in a contracted position on its left side, with the hands up to the face and with the head to the north, in a small, shallow grave, $5 \mathrm{ft}$. by $4 \mathrm{ft}$. in size and about $3 \mathrm{ft}$. deep. The head seemed to have been raised slightly, and a deeper excavation made for the reception of the rest of the body. No relics were found.

Another lay fully extended with the head to the north in a

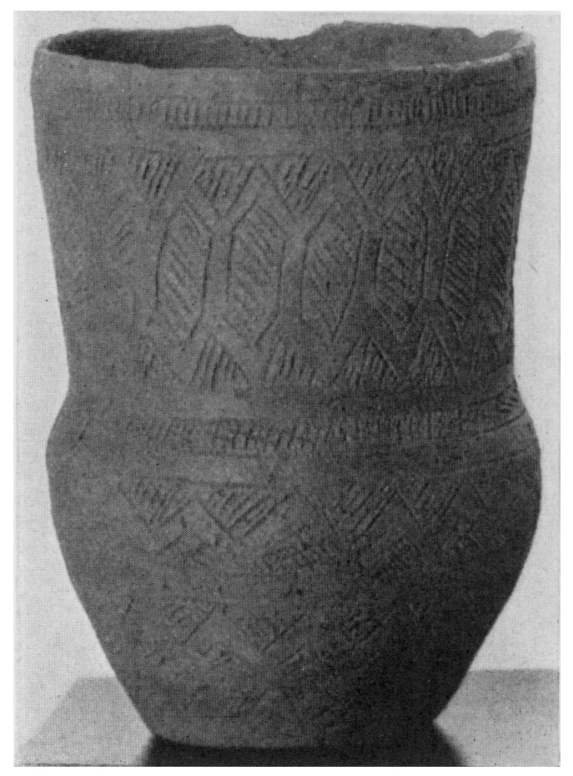

FIg. 14. Beaker from Peterborough.

shallow excavation in the top of the gravel at a depth of about $2 \frac{1}{4} \mathrm{ft}$. Other extended interments are recorded, but since none has furnished relics, their date must remain uncertain failing craniological data, since the site has produced numerous ascertained late Bronze or Early Iron Age burials, in addition to which at one time the gallows stood close by, a fact which might well explain some of them.

It has been observed that in all cases the early interments had been placed on the gravel, but one remarkable exception is to be noted. In this case a contracted skeleton lying on its right side with head to the east had been interred at the bottom of a huthole, $4 \frac{1}{2} \mathrm{ft}$. deep and $8 \mathrm{ft}$. to ro $\mathrm{ft}$. in diameter, on the oldest floor of the hole. 
The only Bronze Age burial with which relics were associated was that of a dolichocephalic adult with wide nose and heavy jaw. The skeleton lay with head to the north-east, on its left side and in contracted position; below the feet and about 3 in. away was a complete beaker of Abercromby's type A. It is a finely made example, of softish paste, varying in colour from red to brown, and measures $7 \frac{1}{2}$ in. in height and 5 in. across the mouth. It is decorated all over with triangles, zigzag bands, hatched and plain. On the neck a sort of lozenge pattern is achieved by joining the points of two plain zigzag bands with plain vertical bands and hatching the intervening spaces (fig. I 4). Near the head of the skeleton was a scraper of elongated type, about $2 \frac{1}{4} \mathrm{in}$. long by $I$ in. wide.

The present account of $\mathrm{Mr}$. Abbott's collections may be terminated by mention of part of the blade of a bronze palstave, and a sherd of pottery (found 8 yds. away) decorated with thongimpressed herring-bone ornament, both from a circular trench, the significance of which must be left for future description, since a similar trench has come to light in another part of the site.

As I have dealt at length with Neolithic pottery in this paper, this occasion seems a suitable one on which to bring to the notice of the Society a recent discovery in Oxfordshire. Early in September last my friend Mr. R. T. Lattey, M.A., and I discovered a small excavation at the top of a quarry near Asthall Barrow, and on exploring it recovered a small quantity of animal bones, etc., including numerous teeth of pig, and a pale grey flint flake or knife. We were unable to complete the exploration at the time, but on two later occasions Mr. Lattey proceeded to the site and finished clearing out the hole, which proved to be circular, about $3 \mathrm{ft}$. in diameter and $2 \mathrm{ft}$. deep. In addition to more bones and teeth he was fortunate enough to recover small fragments of pottery (fig. 15 ).

One is a rather shapeless piece of a rim, of soft black paste with lumps of grit, and on the inner face has some faint indeterminate markings. Two others are, however, unusual and interesting. They belong to what is perhaps one of the smallest Neolithic vessels so far known from the south of England. Like the first piece they are made of soft greasy paste, but are better baked, being light red in colour inside; the larger fragment would seem to have been subjected to fire subsequent to breakage, since the edges are of the same colour as the interior. Both sherds belong to the same pot.

The larger sherd shows a rim with transverse incisions giving 
it a notched appearance; below this is a slight constriction with a row of small holes made with a round, blunt-ended implement, a type of decoration common to late Neolithic pottery in this country. Below the line of holes occurs a type of decoration (visible on both sherds), which I believe is so far without parallel in this country. It consists of curvilinear lines lightly incised.

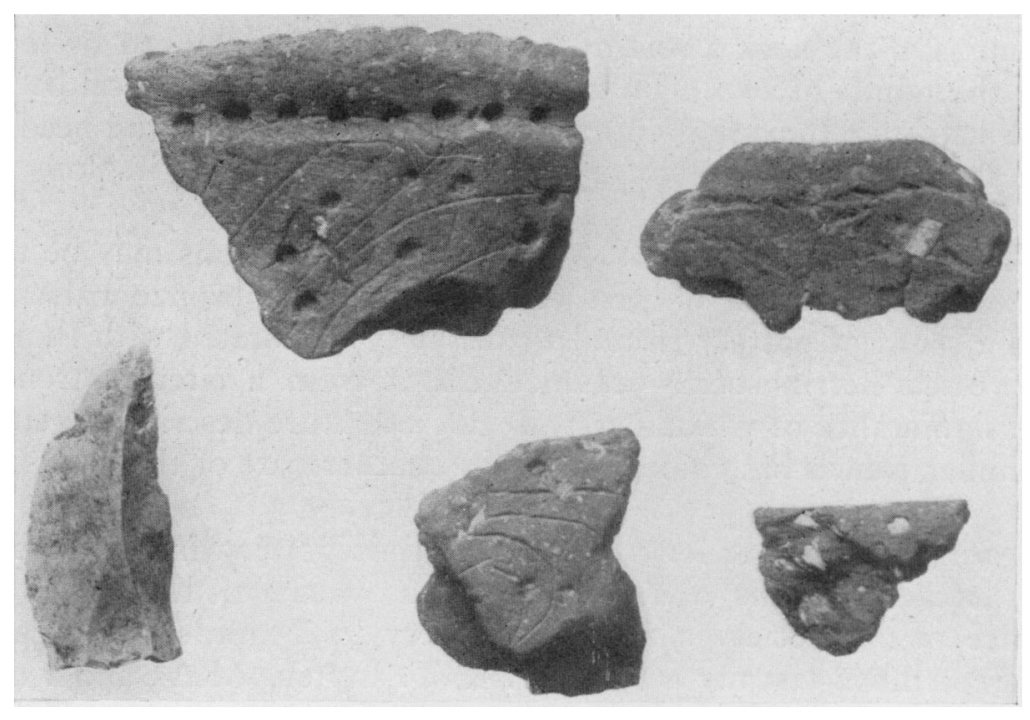

Fig. 15. Pottery from Asthall, Oxon.

In some cases they seem to go in pairs, approximately parallel, with a subsidiary decoration of holes like those round the neck dotted about in a somewhat haphazard fashion. Unfortunately too little remains to make it possible to reconstruct the whole design, so that any comparison with continental pottery decoration must at present be purely tentative. All one can say is that there is something that recalls the Bandkeramik of Neolithic Central Europe, and, if the comparison is an apt one, it would show that our knowledge of the influences which passed from the continent to Britain in Neolithic times is as yet in its infancy.

\section{Discussion}

Mr. Reginald Smith welcomed more specimens of the Neolithic ware exhibited from the Thames last session, and congratulated $\mathrm{Mr}$. Abbott on his discoveries at Peterborough. It seemed to be accepted that the food-vessel was derived from the round-bottomed bowl of the 
Stone Age, and a reference to one of the former type in the Layton Collection at Brent ford might be made to illustrate the survival of certain characteristics (Archaeologia, lxix, 10). At the time of writing that was apparently the only Bronze Age vessel showing curvilinear decoration, and the influence of foreign ribbon-ware (Bandkeramik) had been suggested to account for it. The gradual flattening of the base was confirmed at Peterborough, but it was curious that the half-round hollow moulding below the lip should be at its best in the earliest stage of development. At present the origin of the moulding itself was unexplained. That the type did not accompany the burials found at Peterborough was surprising in view of its occurrence in the long barrow at West Kennett. One fragment showed a different technique, the paste having been impressed with a toothed implement producing a row of hyphens: it was significant that the same decoration was found in Denmark. The 'multiple arch', on the other hand, had a long history that rendered possible an ultimate connexion with the early Mediterranean culture, Brittany perhaps marking a stage in its dispersion, as the device occurred in the dolmens there. The halfcelt from Peterborough, with its thin butt and squared sides ought, according to the current chronology, to date from the dolmen period; and the site might therefore contain remains of the whole megalithic period, ending with the introduction of the foreign beaker. Some of the flints might well be much older, since Peterborough had been one of the few recognized homes of Le Moustier man.

Mr. LEEDS replied that round-and flat-bottomed bowls occurred together, most of the former being ornamented with finger-nail impressions, and the hollow moulding marked and stabbed. Those late characteristics showed that the hemispherical bowl was not confined to the earlier stages of development. 